\title{
High-throughput sequencing of fungal communities across the perennial ice block of Scărişoara Ice Cave
}

\author{
Antonio MONDINI, ${ }^{1}$ ๑ Jonathan DONHAUSER ${ }^{2}$ Corina ITCUS, ${ }^{1}$ Constantin MARIN, \\ Aurel PERS,OIU, ${ }^{1,4,5}$ @ Paris LAVIN, ${ }^{6,7}$ Beat FREY, $^{2}$ Cristina PURCAREA $^{1}$ \\ ${ }^{1}$ Department of Microbiology, Institute of Biology, Bucharest, Romania \\ E-mail: antonio.mondini@icloud.com \\ ${ }^{2}$ Swiss Federal Research Institute WSL, Birmensdorf, Switzerland \\ ${ }^{3}$ Emil Racovita Institute of Speleology, Bucharest, Romania \\ ${ }^{4}$ Stable Isotope Laboratory, Ștefan cel Mare University, Suceava, Romania \\ ${ }^{5}$ Emil Racoviță Institute of Speleology, Cluj-Napoca, Romania \\ ${ }^{6}$ Laboratorio de Complejidad Microbiana y Ecología Funcional, Instituto Antofagasta, Universidad de Antofagasta, \\ Antofagasta, Chile \\ ${ }^{7}$ Departamento de Biotecnología, Facultad de Ciencias del Mar y Recursos Biológicos, Universidad de Antofagasta, \\ Antofagasta, Chile
}

\begin{abstract}
This survey presents the first high-throughput characterisation of fungal distribution based on ITS2 Illumina sequencing of uncultured microbiome from a 1500 years old perennial ice deposit in Scărișoara Ice Cave, Romania. Of the total of 1751957 ITS2 sequences, 64\% corresponded to 182 fungal operational taxonomic units, showing a low diversity, particularly in older ice strata, and a distinct temporal distribution pattern. Ascomycota was the major phylum in all ice samples, dominating the $\mathbf{4 0 0}$ and 1500 years old ice strata deposited during the cold Little Ice Age (LIA) and Dark Ages Cold Period, while Basidiomycota was mostly present in 900-years old ice formed during the Medieval Warm Period (MWP). Chytridiomycota and Mucoromycota phyla were present in recently formed and 400-years old ice, respectively. Among the 80 identified genera, Cryptococcus victoriae, commonly found in glacial habitats, was identified in all strata. A positive correlation between fungal distribution and ice conductivity, $\mathrm{Ca}, \mathrm{Na}$ and $\mathrm{Sr}$ concentrations was observed across the ice block, with $\mathrm{pH}$ values trailing climate variations during LIA and MWP, respectively. Our record highlighted the presence of a complex climate and environmental-driven fungal community in perennial ice strata accumulated during the last $\mathbf{1 5 0 0}$ years in Scărişoara Ice Cave.
\end{abstract}

KEYWORDS: cave ice, ice and climate, ice core, microbiology

\section{INTRODUCTION}

The microbial communities from icy habitats such as polar ice sheets (Skidmore and others, 2000), alpine glaciers (Branda and others, 2010), Arctic glaciers (Adams and others, 2014) and permafrost (Frey and others, 2016), constitute one of the Earth's biomes (Anesio and Laybourn-Parry, 2012). Among these, ice caves are one of the least investigated cold habitats regarding the diversity and ecological role of ice-contained microbiomes (Purcarea, 2018). Microorganisms from perennial ice accumulated in caves became of interest during the last two decades with the isolation of novel cold-adapted bacterial species (Margesin and others, 2003) and the investigation of microbial diversity from ice caves, focused on bacterial communities (Hillebrand-Voiculescu and others, 2013, 2014; Iţcuş and others, 2016, 2018), while only addressing eukaryotic microorganisms based on the 18S rRNA gene (HillebrandVoiculescu and others, 2014; Brad and others, 2018) and internal-transcribed spacer (ITS) (Ogórek, 2018) sequences. Recent studies revealed the presence of fungal communities in different frozen habitats such as permafrost (Ozerskaya and others, 2009), cryoconites (Edwards and others, 2012), subglacial ice (Sonjak and others, 2006) and Antarctic and high-Arctic glaciers (Cantrell and others, 2011). Moreover, the occurrence of particular fungal communities in ice contained caves was mentioned in lava tubes from Mount Erebus, Antarctica (Connell and Staudigel, 2013).

Ice caves are secluded and highly preserved cold habitats representing a new source of cold-adapted microorganisms. The morphology and specific climatic conditions of these caves allowed the accumulation of perennial underground ice deposits constituting paleoclimate archives (Perșoiu and Lauritzen, 2018). Therefore, the ice-entrapped microorganisms could be used as proxies for climate variation studies, while the response of the microbiome composition and abundance to changes in temperature and precipitation regimes during ice formation is expected to reflect the impact of climatic variations on ice depositional processes (Liu and others, 2016).

Scărișoara Ice Cave (Romania), hosting the largest and oldest (>10000 years) underground glacier in the world (Perşoiu and others, 2017), constitutes a model for paleoclimate studies in ice caves (Perşoiu and others, 2017) as 
well as of the diversity, resilience and ecological role of cave ice microbiome (Purcarea, 2018), in order to understand the impact of climate variations on the microbial community structure and activity in this type of glacial habitat. Investigation of the microbiome from the ice block of Scărissoara Ice Cave revealed the presence of complex uncultured (Hillebrand-Voiculescu and others, 2014; Ițcuş and others, 2018) and cultured (Ițcuş and others, 2016) bacterial communities. Cultured fungi were also identified in various cave ice strata using a polymerase chain reaction (PCR)denaturing gradient gel electrophoresis (DGGE) approach (Brad and others, 2018). Although fungi appeared to retain viability for at least a thousand years in ice deposits (Abyzov, 1993; Ma and others, 1999), culture-dependent techniques failed to detect extensive fungal community taxa, while the implementation of molecular techniques allowed the identification of these microbial communities at genus and species levels (Ghosh, 2017). Although the ice geochemistry and climate variations during ice deposition are known to affect the microbiome distribution in various glacial habitats, little is known on the effect of these parameters on environmental fungal communities from perennial cave ice.

This work addresses the lack of knowledge on the temporal distribution of environmental fungal communities in perennial cave ice deposits by investigating the composition of ice-entrenched fungal communities in up to 1500 years old ice layers of Scarisoara cave ice block based on Illumina MiSeq sequencing of the ITS2 region of ribosomal RNA genes, in relation to their geochemical configuration and climate-associated records. To the best of our knowledge, this is the first report on the distribution of environmental fungal diversity in perennial cave ice using high-throughput sequencing.

\section{MATERIALS AND METHODS}

\section{Site description and sample collection}

Scărișoara Ice Cave (Fig. 1) is located in NW Romania $\left(46^{\circ} 29^{\prime} 23.64^{\prime \prime} \mathrm{N}, 22^{\circ} 48^{\prime} 37.68^{\prime \prime} \mathrm{E}\right)$ (Holmlund and others, 2005). This limestone cave, $105 \mathrm{~m}$ deep and $700 \mathrm{~m}$ long, is a single entrance descending cavity located at an altitude of $1165 \mathrm{~m}$ a.s.l. (Fig. 1a). The entrance $(60 \mathrm{~m}$ in diameter, $48 \mathrm{~m}$ deep) gives access to a large chamber (Great Hall) (Fig. 1b). The perennial ice block forms the floor of the Great Hall area. A reduced section of the ice-block surface $\left(\sim 10 \mathrm{~m}^{2}\right)$ in the vicinity of the entrance shaft is exposed to sunlight, containing an abundant phototrophic community (Hillebrand-Voiculescu and others, 2014). Melting and sublimation due to geothermal heat and cold air circulation led to a gradual retreat of the sides of the ice block on the northern part of the Great Hall, resulting in the development of a vertical cliff, where ice layers deposited during the last millennium are visible (Perşoiu and Pazdur, 2011). The ice block was mainly formed by the annual freezing in late autumn of ponded drip, rain/snowmelt and seepage water, overlapping the ice from the previous year (Racoviță, 1927; Perşoiu and others, 2011a). Since drip water is carrying large amounts of organic matter (e.g. soil, pollen, invertebrates), the freezing process resulted in the genesis of a varve-like deposit, comprising both clear ice (1-20 cm thick) and sediment-rich layer (Fig. 1c), including organic material (Racovită and Onac, 2000; Feurdean and others,
2013) and cryogenic precipitated calcite (Žák and others, 2008). The morphology of the cave and the presence of ice determine a peculiar climate (Racoviță, 1994; Perşoiu and others, 2011a), with cold air inflow in winter and thermal stratification in summer, with a layer of warm air floating on the denser, colder air inside the cave. The distal parts of the cave, unglaciated, have positive temperature yearround, while those in the vicinity of the entrance (where the ice block is also present) have temperature variations that follow those outside the cave in winter and stay stable at $0{ }^{\circ} \mathrm{C}$ during summer.

Various geological (Racovită and Onac, 2000) and paleoclimatic (Perșoiu and Pazdur, 2011; Persoiu and others, 2017) studies showed that the perennial ice block inside the cave has accumulated for millennia, containing a high (decadal) resolution record of climate and environment changes during the last 1500 years, including the wellknown cold and dry Little Ice Age (LIA, AD 1250-1860) and Dark Ages Cold Period (DACP, AD 400-800), and the warm and wet Medieval Warm Period (MWP) (AD 8001250) (Perșoiu and Pazdur, 2011; Perșoiu and others, 2017).

\section{Samples collection}

Ice samples were collected from seven different sites within the ice block (Fig. 1d) corresponding to various deposition periods encompassing recent, LIA and MWP intervals, and from strata of high and low organic sediment content, in order to correlate the fungal community distribution in this glacial habitat with paleoclimate records and ice geochemistry. Recently-formed ( 1 year old) ice resulted from the freezing of seepage and rain/snowmelt water accumulated was collected from the surface of the glacier in the Great Hall. Sample 1-S was collected from a sun-exposed cave site near the entrance, while sample 1-L was collected from a similarly-formed ice layer but from an indirect sunlight exposed area in the centre of the Great Hall (Fig. 1a). These samples were collected from the top of the ice block by vertical drilling (Fig. 1e). The 400 (sample 400-O), and 900 (samples 900-O and 900-I) years-old ice samples were collected from the ice wall of Little Reservation (Fig. 1c) by horizontal drilling, after removing $\sim 20 \mathrm{~cm}$ of the surface ice, while 1200 (sample 1200-I) and 1500 (sample 1500-I) years old ice samples were collected from the ice core obtained by vertical drilling in the central area of Great Hall (Fig. 1e). The age of samples 400-O, 900-O and 900-I were determined by ${ }^{14} \mathrm{C}$ dating of macrofossils (leaves and tree branches) collected from the same layers as the samples collected for microbiological analyses (Perșoiu and Pazdur, 2011), while the ages for samples 1200-I and 1500-I were determined by Bayesian interpolation (Blaauw and Christen, 2011) between ${ }^{14} \mathrm{C}$ ages of organic matter trapped in ice (Perșoiu and others, 2017) (Table S1). Samples collected from organic-rich ice layers were labelled with ' $\mathrm{O}$ ' (400-O, 900-O), and ' $\mathrm{I}$ ' (900-I, 1200-I, 1500-I) for those collected from a layer of clear ice, with no visible organic content (Fig. 1c). Sampling was carried out in triplicate from each location, under aseptic conditions, as previously described (Hillebrand-Voiculescu and others, 2014). The ice surface was flamed for 5-10 s prior to the drilling procedure, and both the outer and inner surfaces of the coring auger were decontaminated with $96 \%$ ethanol and flaming after each drilling step. Ice samples were collected in sterilised flasks, in the presence of an open-flame laboratory torch. 


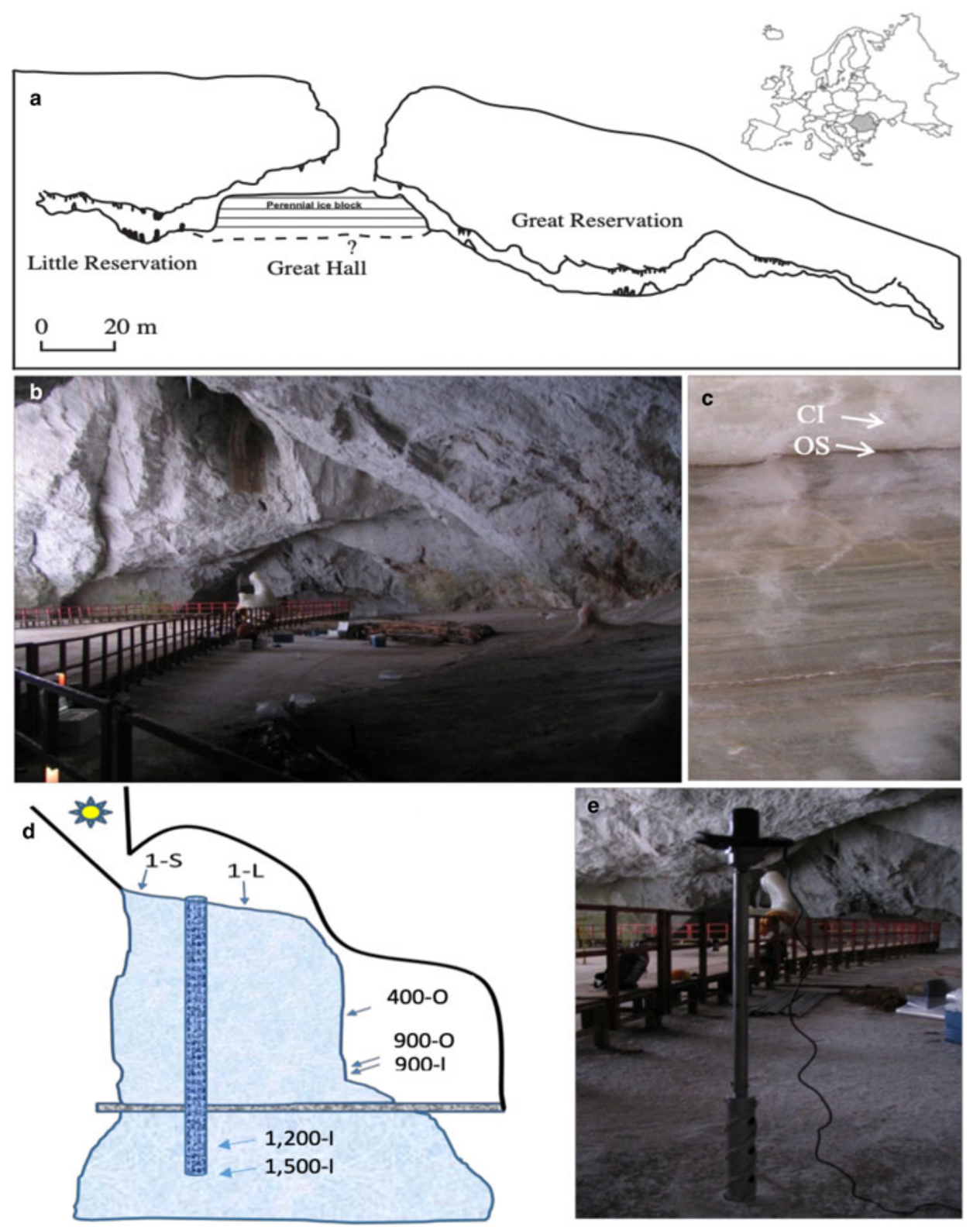

Fig. 1. Scărișoara Ice Cave sampling. (a) Cave map indicating the location of the perennial ice block of undetermined (?) depth (modified from Perșoiu and others, 2011b). (b) Great Hall ice floor constituting the top of the underground ice block (1-S and 1-L ice samples) (photos: C. Purcarea). (c) Little Reservation Ice wall showing horizontal stratification with clear ice (Cl; sample 900-I) and organic sediment (OS; samples 400-O, 900-O). (d) Schematic representation depicting Scărișoara Ice Cave and ice-block morphology with sampling sites annotation. (e) Vertical drilling of the ice block in the Great Hall area.

\section{Geochemical analyses}

Ice samples were melted at $4{ }^{\circ} \mathrm{C}$ and filtered on $0.22 \mu \mathrm{m}$ MFmembranes (Millipore). The $\mathrm{pH}$ and electric conductivity were measured using a S40 SevenMultiTM $\mathrm{pH} / \mathrm{mV}$ meter (Mettler Toledo, USA). Dissolved total carbon (DTC), dissolved inorganic carbon (DIC) and dissolved organic carbon (DOC) contents were determined as previously described (Iţcuş and others, 2016) using a Multi N/C 3100 elemental combustion analyser (Analytic Jena, Germany). Element determinations in melted and filtered water (Hydrogeochemistry Laboratory, Emil Racoviţă Institute of Speleology, Bucharest) were performed by inductivelycoupled plasma mass-spectrometry using a NexION $300 \mathrm{~S}$ system (PerkinElmer, Shelton, CT, USA), in accordance with US-EPA (2014) 6020B standards. Ca concentrations were determined in dynamic reaction cell mode by using
$\mathrm{NH}_{3}$ as a reactive gas. $\mathrm{Na}, \mathrm{K}, \mathrm{Mg}, \mathrm{Sr}, \mathrm{Cu}$ and $\mathrm{Zn}$ concentrations were measured in kinetic energy discrimination mode with $\mathrm{He}$ as an inert gas, while $\mathrm{Cl}$ concentrations were determined using standard mode (US-EPA, 2014). Calibration solutions were purchased from High-Purity Standards ${ }^{\mathrm{TM}}$ (Charleston, SC, USA). For the laboratory control samples, NIST Standard Reference Material ${ }^{\circledR} 1640$ a was used for measuring $\mathrm{Na}, \mathrm{K}, \mathrm{Mg}, \mathrm{Ca}, \mathrm{Sr}, \mathrm{Cu}$ and $\mathrm{Zn}$ contents, and Simulated Seawater Standard (HighPS) for chloride measurements. The uncertainty of the analytical measurements was estimated according to ISO 11352:2012 standard.

\section{DNA extraction}

Ice samples (200-300 mL) were thawed at $4{ }^{\circ} \mathrm{C}$ and filtered on $0.22 \mu \mathrm{m}$ MF-membranes (Millipore) using a vacuum- 
driven stainless-steel filtering system (Millipore) and Chemical Duty Pump, 220 V/50 Hz (Merck Millipore), under sterile conditions. Filters containing biomass were cut into small pieces, and the total microbial DNA was extracted using a Blood and Tissue DNA extraction kit (Qiagen) by a modified protocol including two initial cell lysis steps. After incubation for $1 \mathrm{~h}$ at $37^{\circ} \mathrm{C}$ in the presence of $200 \mu \mathrm{L}$ TE containing 20 units mutanolysin (Fermentas) per $\mathrm{g}$ of filtered cell biomass, to disrupt the microbial cell wall, the cell suspension was incubated for $30 \mathrm{~min}$ at $56^{\circ} \mathrm{C}$ in the presence of 12 units proteinase $\mathrm{K}$ per $\mathrm{g}$ of biomass and ZR bashing beads (Zymo Research), using a Homogenisation system SpeedMill PLUS homogeniser (Analytic Jena), and further cell lysis performed by two cycles of $3 \mathrm{~min}$ on interspersed by two cycles of $3 \mathrm{~min}$ off in order to prevent sample overheating. DNA quantitation assays were assessed using a fluorescence-based Qubit ${ }^{\circledR}$ 2.0 Fluorometer (ThermoFisher Scientific).

\section{Library preparation and Illumina MiSeq sequencing}

PCR were performed to amplify the ITS2 region of the eukaryotic ribosomal operon for the gDNA samples. Each reaction was performed using three different dilutions of the samples $(1 / 50,1 / 100,1 / 2000)$ using a Taq $5 U$-ul Qiagen HotStarTaq with specific primers (Frey and others, 2016) ITS3-CS1 (ACACTGACGACATGGTTCTACACAHCG ATGAAGAACGYRG) and ITS4-CS2 (TACGGTAGCAGAG ACTTGGTCTTCCTSCGCTTATTGATATGC) (CS1 and CS2 tags are underlined). Each DNA fragment was amplified using a PCR thermal cycler (DNA Engine; Bio-Rad, Hercules, CA, USA) with the following thermal cycling conditions: the first cycle consisted of $15 \mathrm{~min}$ at $96{ }^{\circ} \mathrm{C}$, followed by 33 cycles of $30 \mathrm{~s}$ at $96{ }^{\circ} \mathrm{C}, 30 \mathrm{~s}$ at $52{ }^{\circ} \mathrm{C}$ for annealing, $1 \mathrm{~min}$ at $72{ }^{\circ} \mathrm{C}$, and a final incubation for $10 \mathrm{~min}$ at $72{ }^{\circ} \mathrm{C}$. Progressively, after the verification of the PCR products on $2 \%$ agarose gel, the barcoding step was performed adding a barcode to each sample and the sequence of Illumina adapters. For barcoding, 1/50 dilution of the PCR reactions were used with the following thermal cycling conditions: the first cycle consisted of $10 \mathrm{~min}$ at $95^{\circ} \mathrm{C}$, followed by 15 cycles of $15 \mathrm{~s}$ at $95^{\circ} \mathrm{C}, 30 \mathrm{~s}$ at $60^{\circ} \mathrm{C}$ for annealing, $1 \mathrm{~min}$ at $72{ }^{\circ} \mathrm{C}$, and a final incubation for $3 \mathrm{~min}$ at $72{ }^{\circ} \mathrm{C}$. The resulting barcoded amplicons were sequenced using the Illumina MiSeq PE250 bp platform (Génome Québec Innovation Centre, Canada) with the MiSeq Reagent Kit v2 500 cycles from Illumina.

\section{Sequence quality control, operational taxonomic unit (OTU) clustering and taxonomic assignments}

Quality control clustering into OTUs and subsequent taxonomic identification were conducted as previously described (Frey and others, 2016). A customised pipeline based on UPARSE (Edgar, 2013; Edgar and Flyvbjerg, 2015) implemented in USEARCH v. 9.2 (Edgar, 2010) was used by applying the USEARCH fastq mergepairs algorithm (Edgar and Flyvbjerg, 2015) to merge paired-end reads filtering for a minimum length of $300 \mathrm{bp}$. The Bayes Hammer algorithm (Nikolenko and others, 2013) was used to correct substitution errors from phasing events during Illumina sequencing, and Cutadapt software (Martin, 2011) to remove PCR primers, allowing for a maximum of one mismatch in the forward and reverse primer, respectively. Subsequently, the
USEARCH fastq_filter function was used for quality-filtering discarding reads with an expected error of one or greater. To remove singletons, the set of dereplicated sequences was clustered into OTUs at $97 \%$ identity using the cluster_ otu function implemented in USEARCH (Edgar, 2013) that included an 'on the fly' chimera removal algorithm. ITSx software (Bengtsson-Palme and others, 2013, 2015) was used to assess the presence of ribosomal signatures. Sequences were subsequently mapped on the OTU centroid sequences. Taxonomic classification was conducted using the naïve Bayesian classifier classify.seqs function (Wang and others, 2007) implemented in Mothur (Schloss and others, 2009) with a minimum bootstrap support of 0.6. Sequences were queried against the $\mathrm{NCBI}$ database (Sayers and others, 2009), and the OTUs identified as Fungi were further classified using the UNITE database (Nilsson and others, 2015). Nonfungal sequences were removed for downstream analyses. Close relatives of the assigned OTUs were identified using the BLAST (basic local alignment search tool) algorithm and NCBI database (Altschul and others, 1990).

The ITS2 raw sequences were deposited in the NCBI Sequence Read Archive under the BioProject accession number SRP158737.

\section{Statistical analyses}

Observed richness and Shannon diversity were calculated based on nonrarefied OTU abundance matrices. Differences in $\alpha$-diversity (local diversity, Whittaker, 1960) were examined conducting a one-way analysis of variance (ANOVA) in R v.2.15 ( $R$ development Core Team, 2012). Pairwise differences among sites were assessed using Tukey's Honestly Significant Difference (Tukey HSD) posthoc test with the TukeyHSD function (R development Core Team, 2012). Rarefaction curves were calculated using the function rarecurve implemented in the $R$ package vegan. In order to analyse differences in fungal community structures, we calculated Bray-Curtis based on square-root-transformed relative OTU abundances. Statistical evaluation of $\beta$-diversity patterns was performed by conducting a permutational ANOVA (PERMANOVA, number of permutations $=9999$ ) with the function adonis and an analysis of similarity (ANOSIM, number of permutations $=9999$ ) implemented in the vegan $\mathrm{R}$ package (Oksanen and others, 2007). Monte Carlo pairwise comparisons of fungal community structures were conducted using Primer6+. Principal coordinate analysis $(\mathrm{PCoA})$ ordinations were calculated using the ordinate function implemented in the $R$ package phyloseq (McMurdie and Holmes, 2013). Geochemical variables were correlated with PCoA ordination scores using the envfit function implemented in the $R$ package vegan (Oksanen and others, 2007). PCoA and abundance barplots were generated in $\mathrm{R}$ with the ggplot2 package (Wickham, 2016) if not specified otherwise.

\section{RESULTS}

\section{Cave ice geochemical properties}

Geochemical parameters of 1-S, 1-L, 400-O, 900-O, 900-I, 1200-I and 1500-I samples comprising $\mathrm{pH}$, conductivity, concentrations of DTC, DIC, DOC and several specific ions (Table 1) were determined in order to analyse the dependence of ice-contained fungal community composition on 
Table 1. Geochemical properties of Scarisoara ice samples. The $\mathrm{pH}$ and EC, DTC, DIC and DOC concentrations were measured as indicated in Materials and methods section; *previously determined for 1-S, 1-L, 400-O, 900-O and 900-I samples (Iţcuş and others, 2016)

\begin{tabular}{|c|c|c|c|c|c|c|c|}
\hline \multirow[b]{2}{*}{ Parameter (units) } & \multicolumn{7}{|c|}{ Samples } \\
\hline & $1-S$ & $1-\mathrm{L}$ & $400-\mathrm{O}$ & $900-\mathrm{O}$ & 900-I & 1200-I & 1500-I \\
\hline $\mathrm{pH}$ & $7.03 \pm 0.35$ & $7.64 \pm 0.38$ & $7.02 \pm 0.35$ & $7.87 \pm 0.39$ & $7.92 \pm 0.40$ & $6.95 \pm 0.35$ & $6.99 \pm 0.35$ \\
\hline $\mathrm{EC}\left(\mu \mathrm{S} \mathrm{cm}^{-1}\right)$ & $97.3 \pm 9.2$ & $64.9 \pm 6.2$ & $63.2 \pm 6.0$ & $43.7 \pm 4.2$ & $41.7 \pm 4.0$ & $15.2 \pm 1.4$ & $19.6 \pm 1.9$ \\
\hline DTC $\left(\mu g g^{-1}\right)$ & $45.8 \pm 2.3^{*}$ & $22.4 \pm 1.1^{*}$ & $47.7 \pm 2.4^{*}$ & $13.4 \pm 0.7^{*}$ & $9.2 \pm 0.5^{*}$ & $3.0 \pm 0.1$ & $3.9 \pm 0.2$ \\
\hline DIC $\left(\mu g^{-1}\right)$ & $9.4 \pm 0.5^{*}$ & $10.1 \pm 0.5^{*}$ & $15.0 \pm 0.8^{*}$ & $6.4 \pm 0.3^{*}$ & $5.9 \pm 0.3^{*}$ & $1.5 \pm 0.1$ & $2.0 \pm 0.1$ \\
\hline $\mathrm{Ca}\left(\mu \mathrm{g} \mathrm{g}^{-1}\right)$ & $14.3 \pm 0.9$ & $16.2 \pm 1.0$ & $14.5 \pm 0.9$ & $13.0 \pm 0.8$ & $12.0 \pm 0.8$ & $1.1 \pm 0.1$ & $2.2 \pm 0.1$ \\
\hline $\mathrm{Na}\left(\mathrm{ng} \mathrm{g}^{-1}\right)$ & $182.4 \pm 13.9$ & $388.5 \pm 29.6$ & $158.0 \pm 12.1$ & $113.7 \pm 8.7$ & $76.2 \pm 5.8$ & $10.9 \pm 0.8$ & $30.6 \pm 2.3$ \\
\hline $\mathrm{K}\left(\mathrm{ng} \mathrm{g}^{-1}\right)$ & $210.4 \pm 19.6$ & $502.8 \pm 46.9$ & $417.9 \pm 39.0$ & $294.6 \pm 27.5$ & $81.8 \pm 7.6$ & $54.3 \pm 5.1$ & $67.3 \pm 6.3$ \\
\hline$M g\left(n g g^{-1}\right)$ & $120.2 \pm 6.1$ & $295.4 \pm 14.9$ & $213.05 \pm 10.8$ & $219.7 \pm 11.1$ & $49.0 \pm 2.5$ & $8.7 \pm 0.4$ & $10.2 \pm 0.5$ \\
\hline $\operatorname{Sr}\left(n g g^{-1}\right)$ & $5.54 \pm 0.19$ & $7.06 \pm 0.24$ & $5.03 \pm 0.17$ & $6.33 \pm 0.21$ & $4.07 \pm 0.14$ & $0.46 \pm 0.02$ & $1.67 \pm 0.06$ \\
\hline $\mathrm{Cu}\left(\mathrm{ng} \mathrm{g}^{-1}\right)$ & $0.96 \pm 0.06$ & $0.83 \pm 0.05$ & $1.20 \pm 0.08$ & $0.71 \pm 0.05$ & $0.35 \pm 0.02$ & $0.25 \pm 0.02$ & $0.30 \pm 0.02$ \\
\hline $\mathrm{Zn}\left(\mathrm{ng} \mathrm{g}^{-1}\right)$ & $4.74 \pm 0.76$ & $3.48 \pm 0.56$ & $5.06 \pm 0.81$ & $4.24 \pm 0.68$ & $3.63 \pm 0.58$ & $1.56 \pm 0.25$ & $2.05 \pm 0.33$ \\
\hline
\end{tabular}

the (physico)chemical characteristics of ice deposits of different ages from Scarisoara Ice Cave. The $\mathrm{pH}$ ranged from 6.95 to 7.92 across the ice block, with neutral values in most strata except for the clear ice 1-L and both 900-O (pH 7.87) and 900-I ( $\mathrm{pH} 7.92)$ years old samples where the ice deposits were slightly alkaline (7.64-7.92). The electrical conductivity (EC) of melted ice samples showed the highest value $\left(97.3 \mu \mathrm{S} \mathrm{cm}^{-1}\right)$ for the recently-formed ice $1-\mathrm{S}$, and an exponential decrease with the age of ice up to $15.2-19.6 \mu \mathrm{S} \mathrm{cm}^{-1}$ in older ice samples 1200-I and 1500-I (Table 1). DTC was unevenly distributed across the ice block, with high values (45.8-47.7 $\mu^{-1} \mathrm{~g} \mathrm{~g}^{-1}$ ) for the $1-\mathrm{S}$ and $400-\mathrm{O}$ samples, and twofold lower $\left(22.4 \mu^{-1} \mathrm{~g}^{-1}\right)$ in recently formed clear ice 1L. Meanwhile, older ice strata showed a fourfold (900-O and 900-I) and tenfold (1200-I and 1500-I) more reduced DTC content. The DOC content varied in the 3.3-36.4 $\mu \mathrm{g}$ $\mathrm{g}^{-1}$ range, with higher values for $1-\mathrm{S}\left(36.4 \mu \mathrm{g} \mathrm{g}^{-1}\right)$ and 400-O (32.7 $\left.\mu^{-1} \mathrm{~g}^{-1}\right)$, and up to eightfold decreased contents (3.3- $5.7 \mu \mathrm{g} \mathrm{g}^{-1}$ ) in older clear ice strata (Table 1). Among elements, Ca was the dominating ion across the ice block, as expected for a limestone cave deposits (Table 1), with comparable concentrations $\left(14-16.2 \mu \mathrm{g} \mathrm{g}^{-1}\right)$ in the ice layers formed during the last 900 years, and severely decreased values in older ice samples 1200-I $\left(1.1 \mu \mathrm{g} \mathrm{g}^{-1}\right)$ and 1500-I $\left(2.2 \mathrm{\mu g} \mathrm{g}^{-1}\right)$. Na, K, Mg and $\mathrm{Cl}$ concentrations were five to tenfold lower than that of $\mathrm{Ca}$, showing a decrease with the age of ice. Relatively high concentrations of $\mathrm{Cu}, \mathrm{Zn}$ and $\mathrm{Sr}\left(0.25-7.06 \mathrm{ng} \mathrm{g}^{-1}\right)$ were also present in all cave ice samples, with two/fivefold diminution in 1200-I and 1500-I strata, respectively. Chloride ion concentration of $\sim 100 \mathrm{ng} \mathrm{g}^{-1}$ was observed in 1-S and 900-O samples, whereas a twofold higher content was found in 400-O, 1200-I and 1500-I samples. Moreover, the clear ice samples 1-L and 900-I had an eightfold and fivefold higher $\mathrm{Cl}$ concentration that the sun exposed 1-year old ice (1-S), respectively.

\section{Fungal abundance and diversity across Scarisoara ice block}

Illumina MiSeq sequencing of ITS2 region applied to the triplicate ice samples from Scarisoara ice block up to 1500 years old ice layers led to a total of 1751957 sequences ranging in the 62 555-105357 reads per sample interval, with

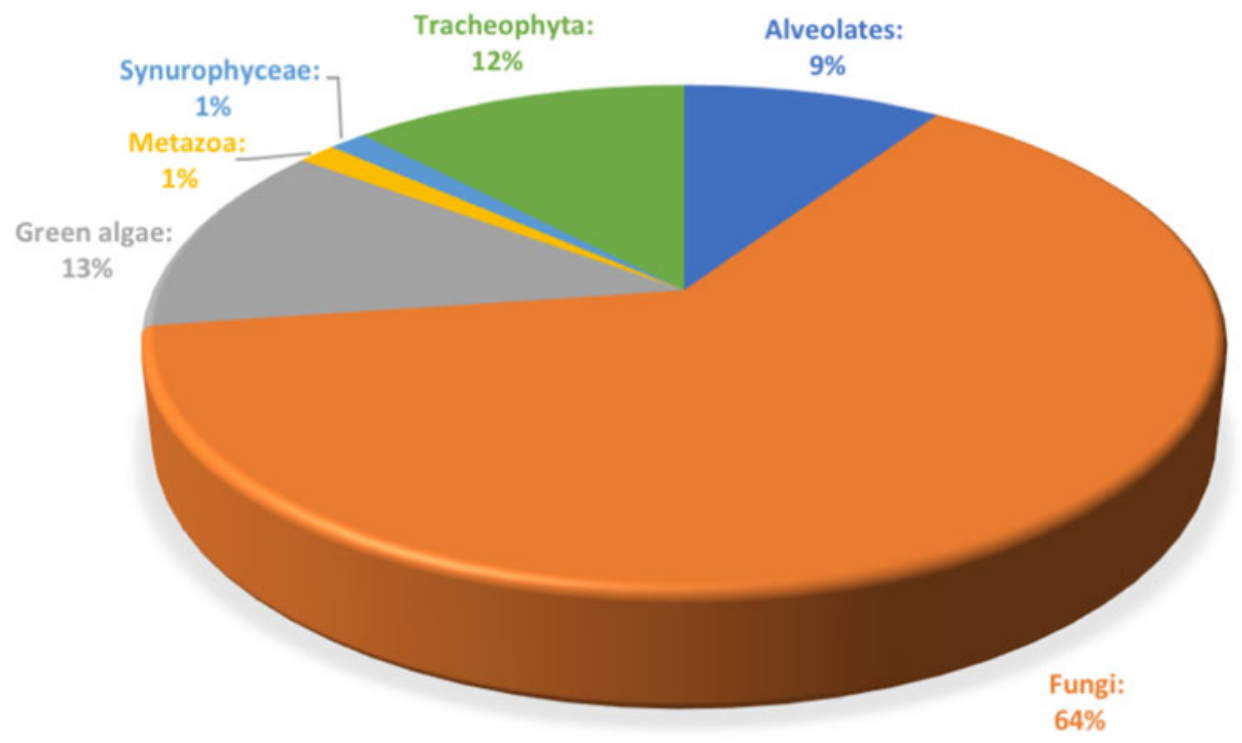

Fig. 2. Relative content of microbial eukaryote ITS2 amplicons identified across the 1500 years Scarisoara ice block. 
an average of 83426.52 reads/sample (33.5 quality) (Table S2). Among the total ITS2 sequences, 64\% were assigned to fungal taxa (Fig. 2), while $13 \%$ belonged to green algae, $12 \%$ to plants (Tracheophyta) and $9 \%$ to Alveolates, besides a low (1\%) presence of Metazoa and Synurophyceae.

After eliminating the nonfungal ITS2 sequences, the resulting 182 fungal OTUs were assigned to four phyla, 16 classes, 37 orders, 63 families and 80 genera. Ascomycota was overall the most abundant (30-90\%) phylum across the ice block, followed by Basidiomycota (5-25\%), Chytridiomycota (20\%) and Mucoromycota (1\%) (previously known as Zygomycota; Spatafora and others, 2016), with $20 \%$ unclassified fungal taxa. The rarefaction curve (Fig. S1) indicated a clearly visible saturation for the fungal communities in older ice strata (400-O, 900-I, 1200-I and $1500-\mathrm{I})$, associated with a low diversity in these samples, in particular for 1200-I and 1500-I. Recently formed ice 1-S and 1-L had a higher number of species (up to 70\%), with large variation between the replicates. No saturation was reached in cases of 900-O and 1200-I, even after 60000 reads (sample size), indicating a partial identification of fungal community composition for these cave ice strata.

The distribution of fungal OTUs in different aged ice strata (Fig. 3) revealed a heterogeneous phylotype occurrence across the cave ice block. Two of the OTUs representing $1.1 \%$ of the fungal community were common to all samples, and 28 OTUs were shared between ice layers of different ages, while 153 OTUs were specifically found in distinct cave ice deposits. The highest number (119) of unique fungal phylotypes, representing $65.4 \%$ of the fungal community, was found in recent ice samples $1-\mathrm{S}$ and $1-\mathrm{L}$, while the older ice contained $2.7 \%$ (400-O), $11 \%$ (900-O and $900-\mathrm{I})$ and $3.8 \%$ (1500-I) less ITS2 amplicons, and only two specific OTU in the $1200-\mathrm{I}$ ice sample $(1.1 \%)$ of total identified fungal phylotypes.

The two fungal OTUs shared among all ice-block layers (Fig. 3) were assigned to Cryptococcus victoriae and

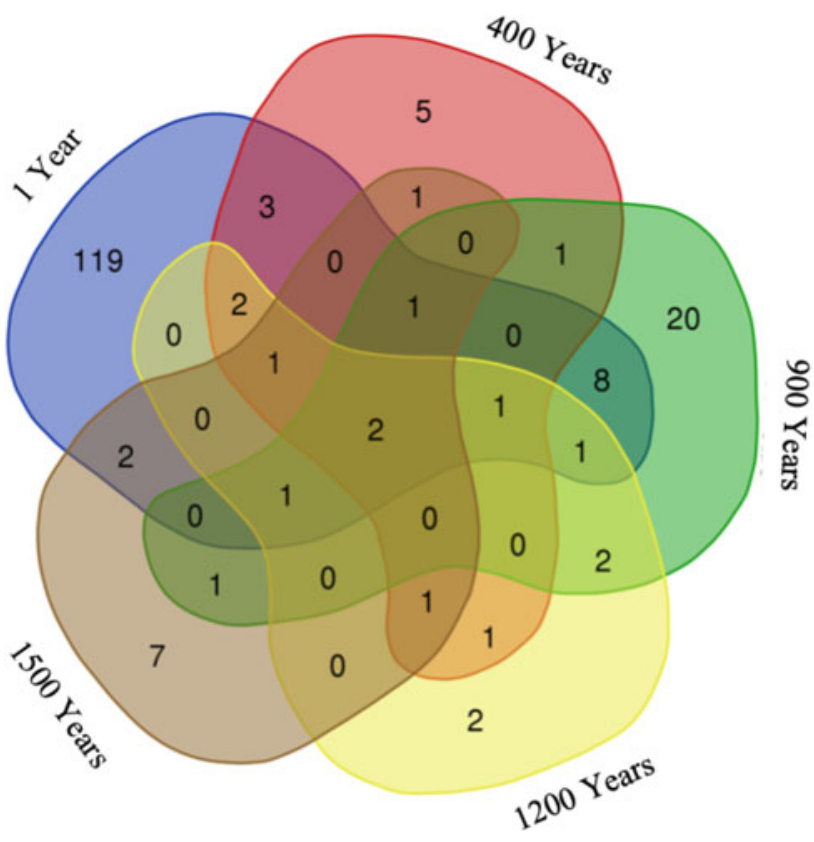

Fig. 3. Distribution of fungal OTUs across Scarisoara ice block. The VENN diagram indicates the number of unique and shared ITS2 OTUs in 1,400,900, 1200 and 1500 years old cave ice layers.
ANTELF16 unclassified fungal species. Recently formed ice deposits (1 year) contained 119 unique OTUs (mostly belonging to the Ascomycota phylum) in which the dominant species comprised Leucosporidiales, Capronia and Helotiales genera, with the presence of two uncultured Cystofilobasidiales and Rhinocladiella sp. Among specific fungal OTUs of 400 years old ice we identified five Mortierella OTUs. In 900 years old ice, 20 unique OTUs belonging to the Basidiomycota phylum were assigned to Rhodotorula, Schizopora and Dioszegia genera. The two OTUs found only in 1200 years old ice corresponded to Chaetothyriales and Agaricomycetes species, while the seven unique OTUs from 1500 years old ice were assigned to Dothideomycetes, Eurotium, Phaeosphaeria, Itersonilia and Fomes species. The shared fungal community between 1 and 900 years old ice strata contained eight members of the Ascomycota, Basidiomycota and Chytridiomycota phyla. Only three OTUs, all belonging to the Ascomycota phylum with one assignment at the genus level (Cadophora sp.), were shared between 1 year and 400 years old ice layers, while a single OTU, assigned to Lyophyllum connatum sp. belonging to Basidiomycota, was commonly present in 400 and 900, and 1200 years old ice samples.

\section{$\alpha$-diversity}

The diversity of the identified fungal community from Scărișoara ice block was relatively low (Fig. 4). Observed richness ranged between 3 and 69 (Fig. 4a) while Shannon diversity ranged between 0.1 and 3.2 (Fig. 4b). Both observed richness and Shannon diversity were significantly $(P<0.05)$ higher in samples 1-L and 1-S as compared to older ice layers, while no significant difference was found among the older ice samples 400-O, 900-O, 900-I, 1200-I and 1500-I (Table 2).

\section{Fungal community structure}

Illumina ITS2 sequencing revealed an unevenly distributed fungal community throughout the ice block (Fig. 5). The relative abundance of fungal phyla (Fig. 5a) indicated that Ascomycota was the major phylum in the cave ice layers formed during the last 1500 years, dominating the older ice samples 900-O, 1200-I and 1500-I (75-80\%), and highly represented in $400-\mathrm{O}(48 \%), 1-\mathrm{L}(60 \%)$ and $1-\mathrm{S}$ $(30 \%)$ ice samples. Meanwhile, this phylum was scarcely distributed $(7 \%)$ in the $900-\mathrm{I}$ sample. OTUs belonging to Basidiomycota were present in all strata formed during the last millennium, ranging from 5 to $10 \%$ in all ice layers, except for the 900-I clear ice sample that appeared highly dominated (90\%) by this taxa and 1500-I sample where it was absent (Fig. 5a). Chytridiomycota phylum was found only in recent ice samples, with higher relative content $(25 \%)$ in the direct sunlight exposed ice $1-S$, while barely $(<1 \%)$ present in the $1-\mathrm{L}$ sample. OTUs within the Mucoromycota phylum were identified only in the $400-\mathrm{O}$ sample $(<1 \%)$. Most of unclassified fungal OTUs $(25 \%)$ were present in both recent ice $1-\mathrm{S}$ and $1-\mathrm{L}$, in $400-\mathrm{O}$ $(30 \%)$, and, to a small extent $(4 \%)$, in the $900-\mathrm{O}$ ice sample.

At the class level (Fig. 5b), Dothideomycetes were found at high relative content $(90 \%)$ in older ice $1500-$ I, and with only low contents (4-10\%) in recent ice 1-S and 1-L samples. The occurrence of this fungal class appeared to decrease in diversity and increase in relative abundance in 

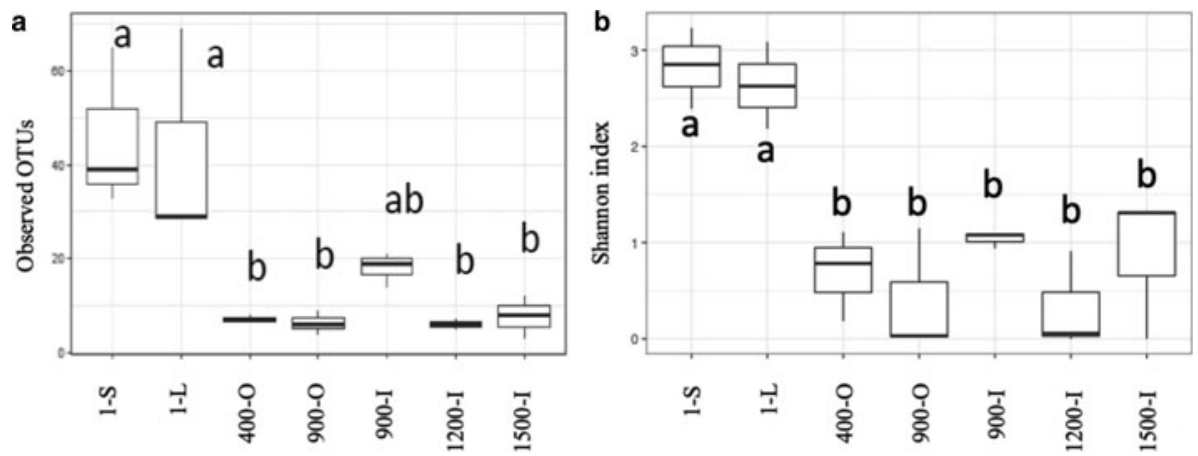

Fig. 4. $\alpha$-diversity indices for fungal OTUs identified in Scărișoara ice block. (a) Observed OTUs and (b) Shannon index variations were measured from triplicate assigned OTUs of 1-S, 1-L, 400-O, 900-O, 900-I, 1200-I and 1500-I ice samples, using the nonrarefied sequences (McMurdie and Holmes, 2014). Letters $(\mathrm{a}, \mathrm{b})$ indicate the significance difference level at $P<0.05$. Horizontal lines represent the median, while the boxes represent the interquartile range of the first and third quartiles. The vertical lines (whiskers) represent the maximal and minimal values.

older ice strata. Overall, a higher relative abundance of classes belonging to the Ascomycota phylum was found in each sample except for 900-I where Microbotryomycetes (Basidiomycota) was the dominant fungal class (60\%). Sordariomycetes (Ascomycota) OTUs were identified in recently formed ice $1-S$ and 1-L (4-10\%), while barely present $(0.5 \%)$ in the $400-\mathrm{O}$ sample and absent in older ice samples (900-I, 1200-I and 1500-I). However, a high representation $(50 \%)$ of this class was found in the $900-\mathrm{O}$ sample characterised by higher organic matter content.
Eurotiomycetes were mainly present in the 1200-I ice $(40 \%)$, and scarcely distributed in the $1-\mathrm{L}$ sample $(5 \%)$, while absent in the remaining ice layers. The unclassified fungal taxa occurred to a large extent (30-55\%) in recent ice 1-S and 1-L, and in 400-O samples, respectively, while only scarcely represented in the $900-\mathrm{O}$ and $1200-\mathrm{I}$ samples $(0,5-2 \%)$. Interestingly, while the unclassified fungi were barely identified in 900-O and completely absent in the $1200-1$ ice layer, the $900-I$ sample was characterised by a high $(45 \%)$ content of unidentified fungi.

Table 2. Statistical differences in $\alpha$-diversity and $\beta$-diversity of fungi in the different analysed ice layers

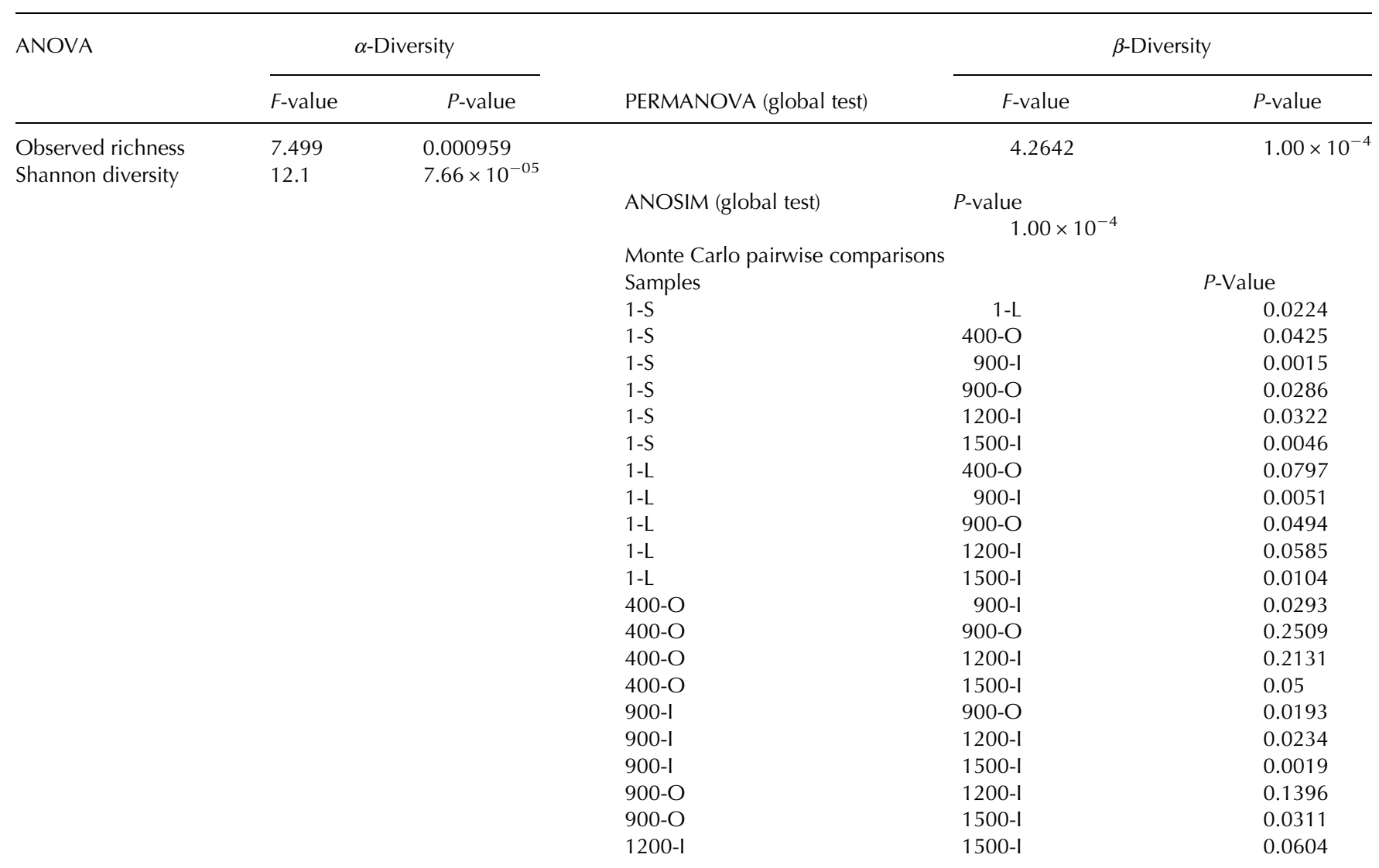

$\alpha$-diversity: a one-way ANOVA was conducted to assess differences by site in observed richness and Shannon diversity followed by Tukey's Honestly Significant Difference (Tukey HSD) post-hoc test. $\beta$-diversity: PERMANOVA and ANOSIM were performed to investigate differences in fungal community structures based on Bray-Curtis distances of square-root-transformed relative abundances. Monte Carlo test was used to assess pairwise differences in community structures between sites. 
a

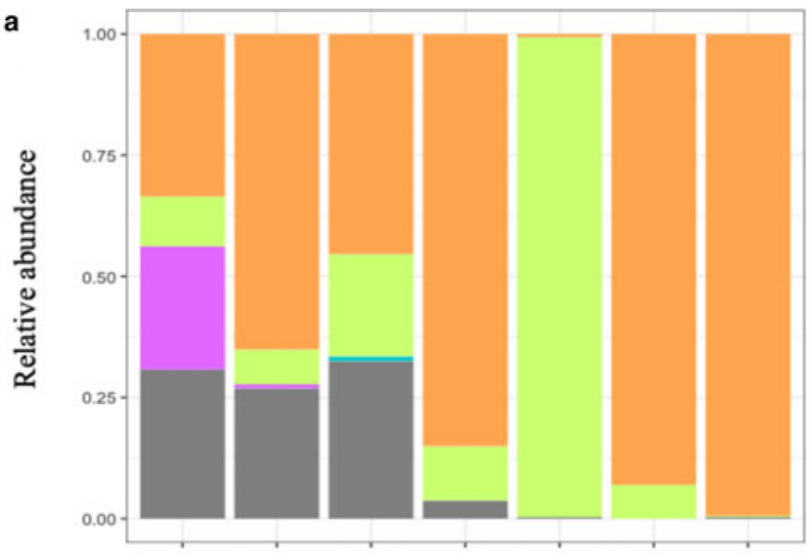

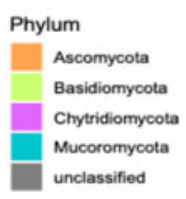

b

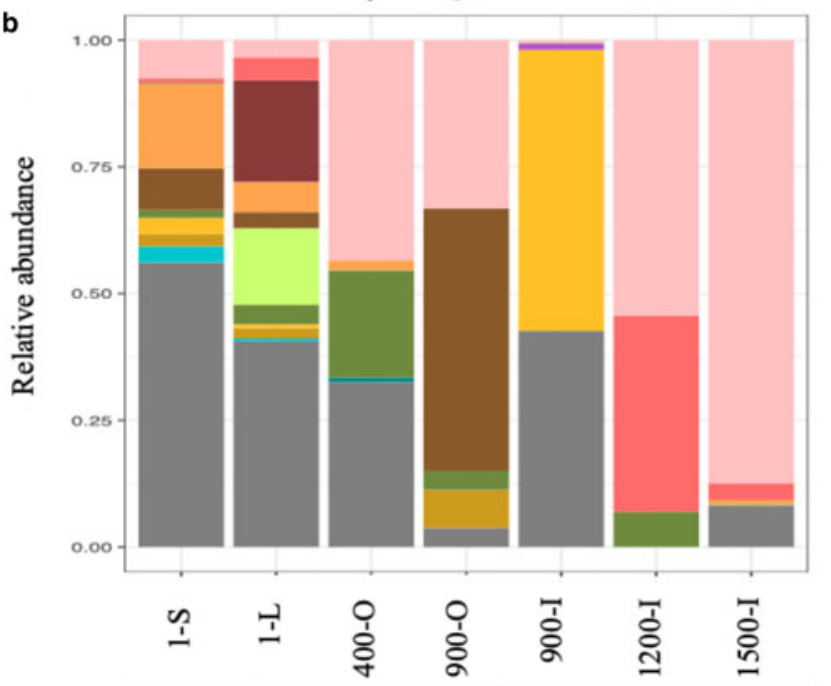

C

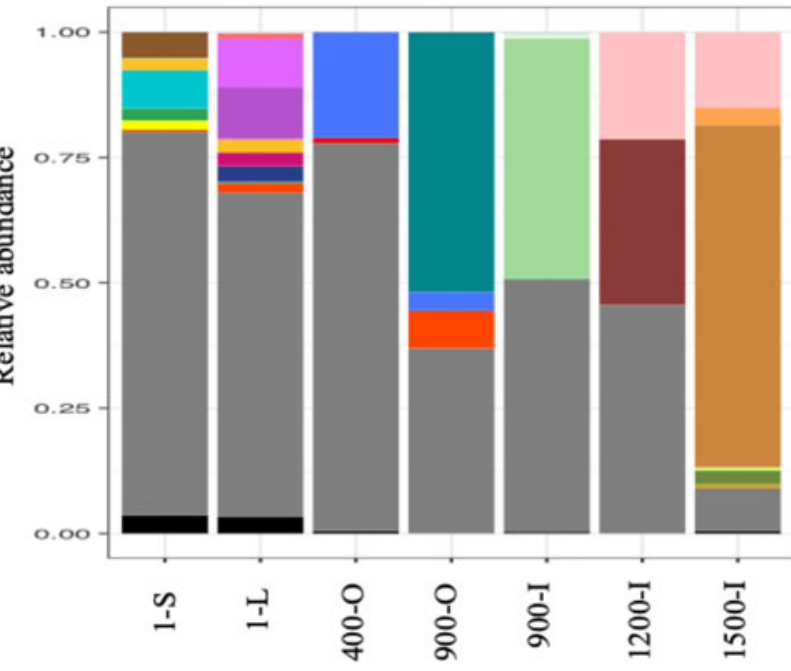

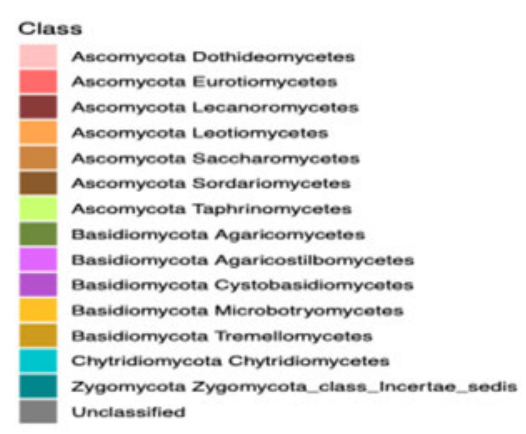

Genus

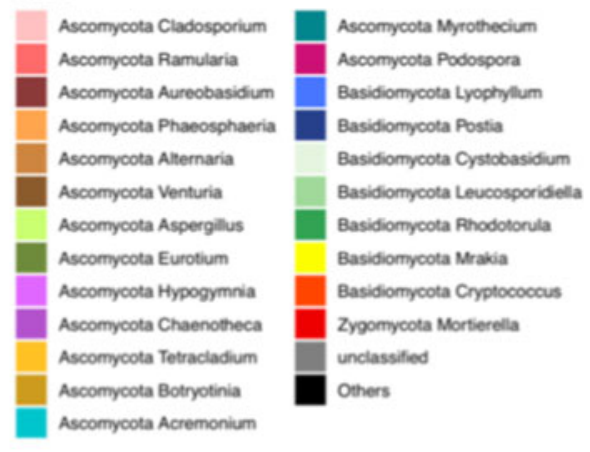

Fig. 5. Relative abundance of the dominant fungal phyla (a), classes (b) and genera (c) in 1-S, 1-L, 400-O, 900-O, 900-I, 1200-I and 1500-I ice samples from Scărișoara Ice Cave based on ITS2 Illumina sequencing.

At the genus level (Fig. 5c), 1-S and 1-L and 1500-I ice samples exhibited a relatively high diversity, while 400-O, 900-O, 900-I and 1200-I ice layers had a lower fungal variability. Lyophyllum sp. was the most abundant genus in the 400-O sample. Myrothecium sp., belonging to Ascomycota, had the highest relative abundance in organic-rich 900-O ice (52\%), while Leucosporidiella sp. (Basidiomycota) constituted the most represented species in clear ice 900-I of the same age. In the 1200-I sample, the most abundant species belonged to Cladosporium and Aureobasidium genera (Ascomycota). An unexpected higher diversity was found in the oldest ice sample 2000-I, counting five genera, with Cladosporium sp. and Alternaria sp. representing 15 and $75 \%$, respectively, of fungal species. Chytridiomycota phylotypes were identified in recently formed ice strata 1-S and 1-L belonging to Rhizophydium sp. and Spizellomycetales sp.

A high relative content of unclassified fungal taxa was found across the cave ice block (25\%), with a higher 


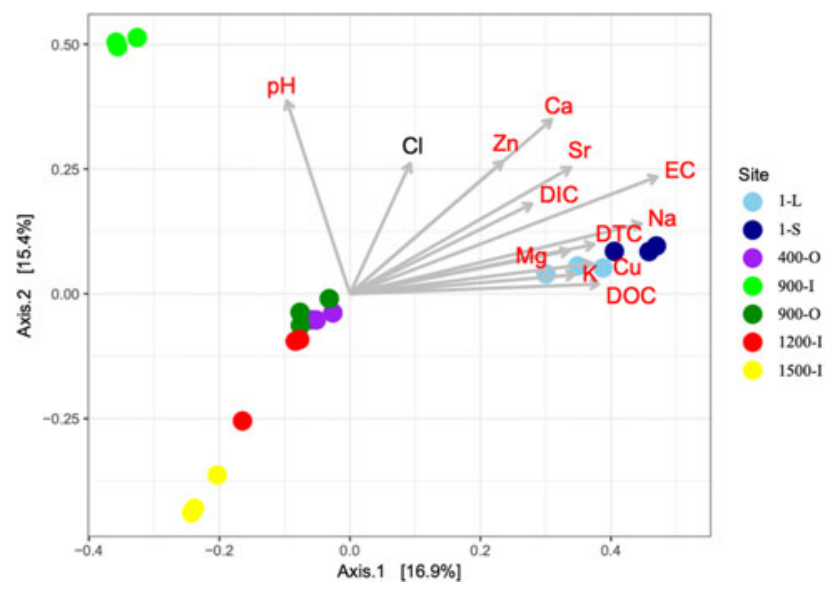

Fig. 6. $\mathrm{PCoA}$ of fungal community structure from $1-\mathrm{S}, 1-\mathrm{L}, 400-\mathrm{O}$, 900-O, 900-I, 1200-I and 1500-I cave ice samples based on BrayCurtis dissimilarities in the seven icy habitats and their correlations with geochemical variables. The variability of the PCoA axes is given in parenthesis.

representation in recently formed ice and decreased with the age of ice, suggesting the presence of a significantly higher fungal diversity in the cave glacier, in particular in younger ice samples. However, this high percentage of unclassified taxa could also be due to DNA degradation in these ice strata, as well as the uncertainty in fungal sequence identification.

\section{$\beta$-diversity and geochemical impact on fungal community structure}

A PCoA analysis of fungal OTUs across the cave ice block in relation to the geochemical parameters (Fig. 6) showed differences in $\beta$-diversity explaining $32.3 \%$ of variation in the community structures with $16.9 \%$ (PCO1 axis) and $15.4 \%$ (PCO2 axis), respectively. Fungal community composition mostly followed the age gradient of the ice samples, with 1 -year old ice forming a very distinct cluster, while community structures from older strata were separated to a smaller extent. Sample 900-I, however, did not follow this pattern but clustered apart from all other samples.

A PERMANOVA analysis revealed significant differences between the sites $\left(P=1 \times 10^{-04}\right)$ which was supported by ANOSIM analysis $(F=4.2642)$. For ice deposits of the same age, Monte Carlo pairwise comparisons revealed significant differences of fungal community structures between 900-O and 900-I samples, whereas a smaller difference was found between the 1-L and 1-S samples. Interestingly the two 900-O and 400-O samples clustered closely together (Table 2), indicating an effect of geochemical composition on the fungal community composition of organic-rich ice deposits from Scarisoara Cave.

All geochemical variables except for $\mathrm{Cl}$ were significantly correlated with the ordination scores of the PCoA of fungal community structure (Fig. 6). EC, Ca, Na and Sr were the variables displaying the strongest correlations $\left(R^{2}=0.7686\right.$, $0.6039,0.6086$ and 0.4959 respectively) and thus best explaining variance in the fungal community structures (Table S3). Most variables were negatively correlated with ice age whereas $\mathrm{pH}$ was only correlated with the differences in fungal community structures in 900-I. Moreover, the carbon content had a major effect on the fungal diversity in the cave ice block, indicating a clear clustering of the recent and older ice strata.

\section{DISCUSSION}

\section{Distinctive ice-entrapped fungal community in 1500- years old cave ice block}

As a new source of biodiversity, Scărisoara Ice Cave microbiome has been investigated during the last decade. These studies, performed by both traditional culture-dependent and cultured-DGGE methods applied to cultured microorganisms (Iţcuş and others, 2016; Brad and others, 2018), revealed the presence of fungi in the perennial ice block harboured in this cave. To overcome the limitations of these applied techniques, recent studies have demonstrated the potential of ITS regions sequencing for quantifying and characterising the fungal diversity in special biological samples (Xia and others, 2016). In order to assess a deeper fungal diversity across the ice block from Scărisoara Ice Cave, we used Illumina MiSeq sequencing of ITS2 amplicons. This approach allowed a direct comparison with fungal community structure from other cold environments such as alpine permafrost (Frey and others, 2016) and alpine glaciers (Branda and others, 2010; Rime and others, 2016).

Our data revealed a nonhomogeneous distribution of fungal taxa throughout Scărişoara Ice Cave layers depending on the age of ice and geochemistry. The identified 182 fungal OTUs were assigned to four phyla, 16 classes, 37 orders, 63 families and 80 genera of fungi. Ascomycota, containing parasitic fungi virtually found in all terrestrial and aquatic ecosystems (Schoch and others, 2009) and playing a major role in recycling dead plant material, was the most abundant (30-90\%) phylum across the perennial ice accumulated during the last 1500 years, with an increasing trend in older ice strata, followed by Basidiomycota (5-25\%), Chytridiomycota (20\%) and Mucoromycota (1\%), with $20 \%$ unclassified fungal taxa. Basidiomycota, common plant pathogens dominating a large variety of cold environments (Buzzini and others, 2017) due to their specific adaptation mechanisms to low temperatures (Vishniac, 2006), occupied a much smaller share of their cave ice fungal community. Chytridiomycota representatives, known as algae and plants parasites associated with liquid water James and others, 2006), were present in recent cave ice (1-S), in accordance with the high abundance of algae in the sun-exposed supraglacial pond formed during the summer period (Hillebrand-Voiculescu and others, 2014). Interestingly, Scărisoara Ice Cave deposit represents, to the best of our knowledge, the first icy habitat reported to harbour this fungal phyla. The cave ice block contained Mortierella sp. (Mucoromycota) known as opportunistic fungi, commonly found in other icy habitats (Fröhlich-Nowoisky and others, 2015). Interestingly, the relative abundance of unclassified fungi appeared to be higher in cave ice strata formed during the last 400 years that could be related to their presence in this ice layer mainly as spores (allegedly parasitic fungi) which are more resistant under frozen conditions, or might correspond to DNA degradation during ice formation. The spore formation could constitute an adaptation mechanism to frozen environments considering the formation of the cave ice deposits by winter freezing of the supraglacial pond accumulated on top of the ice block (Perşoiu and others, 2011a) entrapping microbes that could survive for millennia (Gould, 2006). 
A BLAST analysis of the most abundant OTUs from each ice age deposition (Table S4) indicated the dominance of Ascomycota homologues $(>97 \%$ identity; $E$-value $>5 \times$ $10^{-153}$; query cover $>98 \%$ ) in all strata in addition to Chytridiomycota in recently formed ice, with six of the closest match phylotypes showing a lower (92-96\% identity; $E$-value $>2 \times 10^{-94}$; query cover $>96 \%$ ) identity percentage. These fungi are closely related to species majorly retrieved from plants, particularly trees, rotten/dead wood and soil. Basidiomycota taxa, also widespread throughout the cave ice block (Table S4) was highly represented in 900 years old ice by Leucosporidiella yakutica, Sporidiobolales sp. and Myrothecium sp. (100\% identity) also found in China permafrost, plants (Germany), and soil (USA), respectively. Among these taxa, the psychrophilic yeast belonging to Leucosporidium sp., Sporobolomyces sp. and Malassezia sp. were also dominating the fungal communities of saline Antarctic brines from Northern Victoria land (Borruso and others, 2018), showing their potential to adapt to (poly) extreme environments. As compared to other icy habitats, a unique fungal community was identified in the perennial ice strata of Scărisoara Ice Cave. Basidiomycota appeared to be the dominant taxa fungal communities from glacial environments including Antarctic lake (Gonçalves and others, 2012), Antarctic (Abyzov, 1993), Arctic (Butinar and others, 2007; Dong and others, 2016) and alpine (Branda and others, 2010; Rime and others, 2016) glacier ice isolated from different locations of Antarctica, Europe, USA, China, India and New Zealand. In comparison with Scarisoara cave ice, the fungal community from the sediments of Warren volcanic cave, Antarctica, revealed an equal presence of Ascomycota and Basidiomycota taxa, with the complete absence of Chytridiomycota and Mucoromycota representatives (Connell and Staudigel, 2013). A high relative content of Malassezia sp. (indicator of anthropic contamination) was found in this Antarctic cave, while completely absent in Scărișoara ice block, indicating a clean sampling strategy and low anthropic pollutants considering that Scărișoara Ice Cave is open for tourism. The absence of Malassezia sp. (Basidiomycota) could also be explained by the obligate commensal or parasitic metabolism of this species due to the lack of most of the genes encoding carbohydrate-degradation enzymes (Rime and others, 2016). Moreover, Arctic cryoconites from Svalbard area (Edwards and others, 2012) were majorly composed of Basidiomycota phylotypes, with only few cultured taxa belonging to Ascomycota and the complete absence of Chytridiomycota species, unlike Scarisoara cave ice. Interestingly, the psychrophilic Rhodotorula and Mrakia (Basidiomycota) species able to degrade high molecular weight PAHs and pectate lyase producers (Margesin and others, 2005; Hesham and others, 2012) were present in both icy environments, while the Ascomycota species Articulospora, Preussia and Pseudeurotium were present only in cryoconites (Edwards and others, 2012). These differences could be associated with the different depositional sources of the Arctic cryoconites and perennial ice block from Scarisoara cave.

The cultured fungal community from Scărişoara perennial ice formed during the last 900 years (Brad and others, 2018) revealed the presence of the same four fungal phyla Ascomycota, Basidiomycota, Chytridiomycota and Mucoromycota but with a dissimilar taxa composition and distribution across the ice block at the genera level. Thus,
Mrakia stokesii was the dominating species within the cultured cave ice community, present in all analysed strata, while our survey highlighted the occurrence of $C$. victoriae as the ubiquitously distributed fungal phylotype within the environmental communities across the cave ice block up to 1500 years old strata. This species, also identified in the alpine ice cave (Margesin and others, 2003), was reported as the predominant Basidiomycota yeast in glacial biomes of both Patagonia (Argentina) and the Svalbard archipelago (Norway) (Garcia and others, 2012), also belonging to the most abundant fungal genus identified in soils of the McMurdo Dry Valleys (Connell and Staudigel, 2013). Although the cave ice block was dominated by the phylum Ascomycota, this Basidiomycota species appeared to be present in all ice strata. This could be due to specific adaptation mechanisms to harsh environments of Cryptococcus species leading to a high stress tolerance in glacial habitats (low temperatures and low nutrient concentrations) and ability to degrade organic macromolecules by secreting extracellular hydrolytic enzymes (Garcia and others, 2012).

\section{Impact of climate and ice geochemistry on the fungal community}

The composition of fungal communities entrapped in cave ice layers of different ages appeared to be affected by climate variations during ice deposition, with Ascomycota dominating the ice strata formed during the LIA and DACP and a reduced presence of Mucoromycota phylum, while Basidiomycota was majorly present in 900 years old ice deposited during the warmer and wetter MWP. However, the fungal community composition of the 400 and 1500 years old ice formed during the two cold periods was strongly dissimilar at both class and genus levels, suggesting more complex depositional processes that modelled the fungal community structure within Scărisoara ice block.

Our survey revealed a major representation of plant parasitic fungi and plant/dead wood decomposers belonging to Ascomycota (Schoch and others, 2009) in the 400 (LIA) and 1500 (DACP) years old ice strata formed during the cold intervals. Among these, Phaeosphaeria sp., known as necrotrophic and saprobic species for a wide range of plants (Quaedvlieg and others, 2013), appeared to be one of the most abundant phylotype of the 1500 years old cave ice layer (Table S4). This OTU was also found in Antarctic soil, confirming the widespread of fungal species in various frozen habitats worldwide. Moreover, ice strata formed during the cold periods had a high relative content of the plant pathogens Mycosphaerella sp. (Crous, 2009) and Alternaria sp. (Woudenberg and others, 2015), also found in various tree species (beech, Picea abies, and Kunzea ericoides) from cold/alpine and dry habitats (Table S4). During these intervals, the surrounding vegetation of Scărișoara Ice Cave was dominated by spruce ( $P$. abies) forests (Feurdean and others, 2011), that appeared to be a favourable host for parasitic Ascomycota fungi (Jasalavich and others, 2000). This climate driven preferred vegetation was confirmed by the presence of Cadophora sp. (OTU 210) and uncultured fungal taxa isolated from pine and spruce trees (OTU 22) in the LIA-formed ice sample 400-O.

Members of Basidiomycota were highly present in 900-I ice formed during the warmer and wetter MWP. Taxa affiliated to the Microbotryomycetes class were mainly present in the 900 years old clear ice layer, corresponding 
to a variety of black yeasts belonging to Mrakia sp., C. victoriae and Rhodotorula sp. (Kan and others, 2018). These phylotypes, also found in cultured fungal communities from Scărisoara Ice Cave in both 1 and 900 years old ice layers (Brad and others, 2018), have been recently identified in 10000 years old permafrost from Swiss Alps (Frey and others, 2016).

Based on these observations, the fungal community from this glacial habitat appeared to constitute a putative reservoir for identification of microbial proxies for climate variations, considering the dominance of Ascomycota and Basidiomycota taxa associated with warmer and colder climatic periods, respectively.

The geochemical composition in different horizons of ice could be associated with climate variations that could affect the ice deposition process. Thus, the cold and dry conditions reduced the hydrological cycle and precipitation rate, increasing the aerosols and dust residence time and allowing their dispersion to great distances. Various element ice contents related to the genesis of the deposited aerosols, where $\mathrm{Ca}$ is a well-known ion indicator of terrestrial dust (Zhang and others, 2006), high $\mathrm{Na}$ and $\mathrm{Cl}$ concentrations correspond to sea salt aerosol origin, and high of $\mathrm{SO}_{4}$ and $\mathrm{Cl}$ concentrations to a significant volcanic aerosol deposition (Miteva and others, 2009). Our data indicated a dominant terrestrial dust deposition based on the high concentration of $\mathrm{Ca}$ in all ice strata, whereas a small concentration of $\mathrm{Na} / \mathrm{Cl}$ could lead to a scarce deposition of sea-originating aerosol. The distribution of fungal community across Scarisoara cave ice block showed a high correlation with Ca concentrations, in particular during colder periods, which could result from more cryogenic carbonate formation during prolonged and/ or intensive freezing periods (Žák and others, 2008). Interestingly, the cave ice layers $400-\mathrm{O}$ and $1500-\mathrm{I}$ formed during the cold periods were characterised by neutral $\mathrm{pH}$ values, while the ice formed during the MWP was slightly alkaline, suggesting a $\mathrm{pH}$-driven fungal community structure in this glacial habitat. During these colder periods, $P$. abies forests dominated the cave's surroundings, allegedly inducing a lower soil pH due to the high content of shikimic and quinic acids contained in needles falling on the ground (Lindner and Grill, 1978). Meanwhile, the fungal diversity of 900-O and 900-I ice layers formed during MWP showed a significantly different response to $\mathrm{pH}$, with a clear clustering of 900-I sample, unlike the bacterial communities from these ice strata that had a similar response to $\mathrm{pH}$ (Ițcuş and others, 2016). In addition, the presence in the recently formed cave ice of Hypogymnia species (Table S4) known as organic acid compounds fungal producers (Białońska and Dayan, 2005) could be explained by the lower $\mathrm{pH}$ values of these ice deposits.

The organic carbon content of ice strata also appeared to play a modelling role of the fungal community in Scărișoara Ice Cave. A relatively low occurrence of Basidiomycota OTUs was found across the Scarisoara ice block $(\sim 10 \%$ relative abundance) except for the clear ice sample 900-I (90\%), characterised by the lowest DOC content and higher $\mathrm{pH}$, suggesting that taxa belonging to this phylum are outcompeted by saprotrophs in the presence of high DOC contents, although the basidiomycetous yeast Cryptococcus sp. was widespread across the ice layers sustained by its cellulolytic and hemicellulolytic activities (Rime and others, 2016), and by a particular cell wall composition enabling this species to withstand a wide $\mathrm{pH}$ range (Garcia and others, 2012).
However, no significant variation of this taxa representation was observed in the 1-S and 1-L samples, suggesting a more complex modelling mechanism of the fungal community in recent ice deposits. Moreover, one of the dominating species of the 900 years old ice (Table S4) was the lichenised Ascomycota Myrothecium sp., representing a potent cellulose decomposer (Haghighi and Shahdoust, 2015), in accordance with the low DOC content of this ice layer.

\section{CONCLUSION}

This study provided the first high-throughput sequencing across 1500 years old ice revealing a broad fungal diversity in Scărișoara Ice Cave. Various factors such as age of ice, substrate geochemistry and climate patterns during ice formation appeared to influence the diversity and distribution of fungi in the perennial cave ice block. The current data sustain the possibility to identify fungal biomarkers for climate variations in this cave perennial ice, consolidating the relationships between microbial population and environmental characteristics. Further investigations of ice-entrapped microorganisms will extend the assessment of microbiome composition and role in this habitat, improving our understanding on the effect of local climate on the origin and microbial composition at different ice depths. Moreover, novel fungal strains could be further identified and screened for various biotechnological applications using the identified cave ice taxa.

\section{SUPPLEMENTARY MATERIAL}

The supplementary material for this article can be found at https://doi.org/10.1017/aog.2019.6

\section{ACKNOWLEDGEMENTS}

We thank Christian A. Ciubotărescu, Alexandra HillebrandVoiculescu, Traian Brad, Madalina D. Pascu, Bogdan P. Onac, Carmen Bădălută and Viorica Nagavciuc for assistance with ice sampling, and Pablo Arán Sekul for bioinformatics support. This work was financially supported by the H2020 EraNet-LAC ELAC2014/DCC0178 Joint Program and UEFISCDI grants PN-II-ID-PCE-2011-3-0742 and PNIII-P1-1.1-TE-2016-2210. This project has received funding from the European Union's Horizon 2020 research and innovation programme under the Marie Skłodowska-Curie grant agreement No. 675546.

\section{AUTHOR CONTRIBUTIONS}

$\mathrm{AM}$ and $\mathrm{CP}$ wrote the manuscript, with important contribution from AP. Cl and AP participated in ice sampling; $\mathrm{Cl}$ conducted the sample filtration and DNA extraction; BF performed the bioinformatics analyses; BF and JD carried out the statistical analyses; PL performed BLAST sequence analysis; CM conducted the geochemical analyses; AP contributed to ${ }^{14} \mathrm{C}$ radiocarbon ice dating; $\mathrm{CP}$ performed the experimental design and coordinated the project. All of the authors contributed to data interpretation and revision of the manuscript and approved its final version.

\section{REFERENCES}

Abyzov SSG (1993) Microorganisms in the Antarctic ice. In Friedman El ed. Antarctic microbiology. John Wiley \& Sons, Inc., New York, 265-295. 
Adams HE, Crump BC and Kling GW (2014) Metacommunity dynamics of bacteria in an Arctic lake: the impact of species sorting and mass effects on bacterial production and biogeography. Front. Microbiol., 5, 82 (http://dx.doi.org/10.3389/fmicb. 2014.00082)

Altschul SF, Gish W, Miller W, Myers EW and Lipman DJ (1990) Basic local alignment search tool. J. Mol. Biol., 215, 403-410

Anesio AM and Laybourn-Parry J (2012) Glaciers and ice sheets as a biome. Trends Ecol. Evol., 27(4), 219-225 (doi: 10.1016/j. tree.2011.09.012)

Bengtsson-Palme J and 20 others (2013) Improved software detection and extraction of ITS1 and ITS2 from ribosomal ITS sequences of fungi and other eukaryotes for analysis of environmental sequencing data. Methods Ecol. Evol., 4(10), 914-919 (https://doi.org/10.1111/2041-210X.12073)

Bengtsson-Palme J and 6 others (2015) METAXA2: improved identification and taxonomic classification of small and large subunit rRNA in metagenomic data. Mol. Ecol. Resour., 15(6), 14031414 (doi: 10.1111/1755-0998.12399)

Białońska D and Dayan FE (2005) Chemistry of the Lichen Hypogymnia physodes transplanted to an industrial region. J. Chem. Ecol., 31(12), 2975-2991 (doi: 10.1007/s10886-0058408-x)

Blaauw M and Christen JA (2011) Flexible paleoclimate age-depth models using an autoregressive gamma process. Bayesian. Anal., 6(3), 457-474 (doi: 10.1214/ba/1339616472)

Borruso and 8 others (2018) A thin ice layer segregates two distinct fungal communities in Antarctic brines from Tarn Flat (Northern Victoria Land). Sci. Rep., 8, 6582 (doi: 10.1038/s41598-01825079-3)

Brad T and 6 others (2018) Fungi in perennial ice from Scărișoara Ice Cave (Romania) Scientific Reports, 8, 10096 (doi: 10.1038/ s41598-018-28401-1)

Branda E and 5 others (2010) Yeast and yeast-like diversity in the southernmost glacier of Europe (Calderone Glacier, Apennines, Italy). FEMS Microbiol. Ecol., 72, 354-369 (doi: 10.1111/ j.1574-6941.2010.00864.x)

Butinar L, Spencer-Martins I and Gunde-Cimerman N (2007) Yeasts in high Arctic glaciers: the discovery of a new habitat for eukaryotic microorganisms. Antonie van Leeuwenhoek, 91, 277-289 (doi: 10.1007/s10482-006-9117-3)

Buzzini P, Turk M, Perini L, Turchetti B and Gunde-Cimerman N (2017) Yeasts in Polar and Subpolar Habitats. In: Buzzini P, Lachance MA and Yurkov A (eds) Yeasts in Natural Ecosystems: Diversity. Springer, Cham (doi: 10.1007/978-3-319-62683-3_11)

Cantrell SA, Dianese JC, Fell J, Gunde-Cimerman N and Zalar P (2011) Unusual fungal niches. Mycologia, 103, 1161-1174 (doi: 10.3852/11-108)

Connell L and Staudigel H (2013) Fungal diversity in a dark oligotrophic volcanic ecosystem (DOVE) on Mount Erebus, Antarctica. Biology (Basel), 2(2), 798-809 (doi: 10.3390/biology2020798)

Crous PW (2009) Taxonomy and phylogeny of the genus Mycosphaerella and its anamorphs. Fungal Divers., 38, 1-24

Dong K and 6 others (2016) Soil fungal community development in a high Arctic glacier foreland follows a directional replacement model, with a mid-successional diversity maximum. Sci. Rep., 6, 26360 (doi: 10.1038/srep26360)

Edgar RC (2010) Search and clustering orders of magnitude faster than BLAST. Bioinformatics, 26(19), 2460-2461 (doi: 10.1093/ bioinformatics/btq461)

Edgar RC (2013) UPARSE: highly accurate OTU sequences from microbial amplicon reads. Nat. Methods, 10(10), 996-998 (doi: 10.1038/nmeth.2604)

Edgar RC and Flyvbjerg H (2015) Error filtering, pair assembly and error correction for next generation sequencing reads. Bioinformatics, 31 (21), 3476-3482 (doi: 10.1093/bioinformatics/btv401)

Edwards A and 6 others (2012) A distinctive fungal community inhabiting cryoconite holes on glaciers in Svalbard, 6(2), 168-176 (https://doi.org/10.1016/j.funeco.2012.11.001)
Feurdean A, Perşoiu A, Pazdur A and Onac BP (2011) Evaluating the palaeoecological potential of pollen recovered from Ice in caves: a case study from Scarisoara Ice Cave, Romania. Rev. Palaeobot. Palynol., 165(1-2), 1-10 (doi: 10.1016/j.revpalbo.2011.01.007)

Feurdean A and 5 others (2013) Biodiversity variability across elevations in the Carpathians: parallel change with landscape openness and land use. Holocene, 23(6), 869-881 (https://doi.org/ 10.1177/0959683612474482)

Frey B and 6 others (2016) Microbial diversity in European alpine permafrost and active layers. FEMS Microbiol. Ecol., 92, 1-17 (doi: 10.1093/femsec/fiw018)

Fröhlich-Nowoisky J and 5 others (2015) Ice nucleation activity in the widespread soil fungus. Mortierella Alpina Biogeosci., 12, 1057-1071 (doi: 10.5194/bg-12-1057-2015)

Garcia V, Zalar P, Brizzio S, Gunde-Cimerman N and Broock M (2012) Cryptococcus species (Tremellales) from glacial biomes in the southern (Patagonia) and northern (Svalbard) hemispheres. FEMS Microbiol. Ecol., 82, 523-539 (doi: 10.1111/j.15746941.2012.01465.x)

Ghosh S and 7 others (2017) In situ cultured bacterial diversity from iron curtain cave, Chilliwack, British Columbia, Canada. Diversity. (Basel), 9, 36 (doi: 10.3390/d9030036)

Gonçalves VN, Vaz ABM, Rosa CA and Rosa LH (2012) Diversity and distribution of fungal communities in lakes of Antarctica. FEMS Microbiol. Ecol., 82(2), 459-471 (https://doi.org/10.1111/ j.1574-6941.2012.01424.x)

Gould GW (2006) History of science spores. J. Appl. Microbiol., 101 (3), 507-513 (doi: 10.1111/j.1365-2672.2006.02888.x)

Haghighi MT and Shahdoust E (2015) Molecular detection of endophytic Myrothecium spp. by ITS-sequencing technique. Int. J. Res. Stud. Biosci., 3(1), 60-66

Hesham A and 5 others (2012) Biodegradation of high molecular weight PAHs using isolated yeast mixtures: application of meta-genomic methods for community structure analyses. Environ. Sci. Pollut. Res. Int., 19(8), 3568-3578 (doi: 10.1007/s11356-012-0919-8)

Hillebrand-Voiculescu A and 8 others (2013) Bacterial 16S rRNA gene clone library from recent ice stalagmites of Scărişoara cave. Rom. J. Biochem., 50, 109-118

Hillebrand-Voiculescu A and 9 others (2014) Searching for coldadapted microorganisms in the underground glacier of Scarisoara Ice Cave, Romania. Acta Carsol., 43(2-3), 319-329 (doi:https://doi.org/10.3986/ac.v43i2-3.604)

Holmlund P and 6 others (2005) Assessing the palaeoclimate potential of cave glaciers: the example of the Scărişoara Ice Cave (Romania). Geogr. Ann. Ser. A: Phys. Geogr., 87(1), 193-201 (doi: 10.1111/j.0435-3676.2005.00252.x)

Iţcuş C, Pascu MD, Brad T, Perşoiu A and Purcarea C (2016) Diversity of cultured bacteria from the perennial ice block of Scărişoara Ice Cave, Romania. Int. J. Speleol., 45(1), 89-100 (doi.org/10.5038/1827-806X.45.1.1948)

Iţcuş $C$ and 5 others (2018) Bacterial and archaeal community structures in perennial cave ice. Sci. Rep., 8, 15671 (doi: 10.1038/ s41598-018-34106-2)

James TY and 7 others (2006) A molecular phylogeny of the flagellated fungi (Chytridiomycota) and description of a new phylum (Blastocladiomycota). Mycologia, 98, 860-871 (http://dx.doi. org/10.1080/15572536.2006.11832616)

Jasalavich CA, Ostrofsky A and Jellison J (2000) Detection and identification of decay fungi in spruce wood by restriction fragment length polymorphism analysis of amplified genes encoding rRNA. Appl. Environ. Microbiol., 66(11), 4725-4734 (doi: 10.1128/AEM.66.11.4725-4734.2000)

Kan G and 6 others (2018) Copper stress response in yeast Rhodotorula mucilaginosa AN5 isolated from sea ice, Antarctic. Microbiologyopen., 2018, e657 (https://doi.org/10.1002/mbo3.657)

Lindner W and Grill D (1978) Siuren in koniferennadeln. Phyton (Horn, Austria), 18, 137-144

Liu $\mathrm{Y}$ and 14 others (2016) Bacterial responses to environmental change on the Tibetan Plateau over the past half century. Environ. Microbiol., 18(6), 1930-19412 (doi: 10.1111/1462-2920.13115) 
Ma LJ, Catranis CM, Starmer WT and Rogers SO (1999) Revival and characterization of fungi from ancient polar ice. Mycologist, 13, 70-73 (doi: 10.1016/S0269-915X(99)80012-3)

Margesin R, Gander S, Zacke G, Gounot AM and Schinner F (2003) Hydrocarbon degradation and enzyme activities of cold-adapted bacteria and yeasts. Extremophiles, 7, 451-458 (doi: 10.1007/ s00792-003-0347-2)

Margesin R, Fauster V and Fonteyne PA (2005) Characterization of cold-active pectate lyases from psychrophilic Mrakia frigida. Lett. Appl. Microbiol., 40(6), 453-459 (doi: 10.1111/j.1472765X.2005.01704.x)

Martin M (2011) Cutadapt removes adapter sequences from highthroughput sequencing reads. Ann. Glaciol., 17(1), 10-12 (doi: https://doi.org/10.14806/ej.17.1.200)

McMurdie PJ and Holmes S (2013) Phyloseq: an R package for reproducible interactive analysis and graphics of microbiome census data. PLoS One, 8(4), e61217 (https://doi.org/10.1371/ journal.pone.0061217)

McMurdie PJ and Holmes S (2014) Waste not, want not: why rarefying microbiome data is inadmissible. PLoS Comput. Biol., 10(4), e1003531 (https://doi.org/10.1371/journal.pcbi.1003531)

Miteva V, Teacher C, Sowers T and Brenchley J (2009) Comparison of the microbial diversity at different depths of the GISP2 Greenland ice core in relationship to deposition climates. Environ. Microbiol., 11(3), 640-656 (doi: 10.1111/j.14622920.2008.01835.x)

Nikolenko SI, Korobeynikov AI and Alekseyev MA (2013) Bayeshammer: Bayesian clustering for error correction in singlecell sequencing. BMC Genomics, 14, S7 (https://doi.org/10.1186/ 1471-2164-14-S1-S7)

Nilsson (2015) METAXA2: improved identification and taxonomic classification of small and large subunit rRNA in metagenomic data. Mol. Ecol. Resour., 15(6), 1403-1414 (doi: 10.1111/1755-0998.12399)

Ogórek R (2018) Fungal communities on Rock surfaces in Demänovská Ice Cave and Demänovská Cave of liberty (Slovakia). Geomicrobiol. J., 35, 266-276 (doi: 10.1080/01490451.2017.1348409)

Oksanen J and 6 others (2007) The vegan package. Community Ecol. Package, 10, 631-637

Ozerskaya S, Kochkina G, Ivanushkina N and Gilichinsky DA (2009) Fungi in permafrost. In Margesin R ed. Permafrost soils. Soil biology, vol. 16, Permafrost Soils. Springer, Berlin, Heidelberg, 85-95 (doi.org/10.1007/978-3-540-69371-0_7)

Persoiu A and Lauritzen SE (2018) Ice caves. Amsterdam, Netherlands: Elsevier (https://doi.org/10.1016/C2016-0-01961-7)

Persoiu A and Pazdur A (2011) Ice genesis and its long-term mass balance and dynamics in Scarisoara Ice Cave, Romania. Cryosphere, 5, 45-53 (doi: 10.5194/tc-5-45-2011)

Perşoiu A, Onac BP and Perşoiu I (2011a) The interplay between air temperature and ice dynamics in Scărişoara Ice Cave, Romania. Acta Carsologica, 40(3), 445-456 (http://dx.doi.org/10.3986/ac. v40i3.4)

Perşoiu A, Onac BP, Wynn J, Bojar AV and Holmgren K (2011b) Stable isotopes behavior during cave ice formation by water freezing in Scărişoara Ice Cave. J. Geophys. Res. - Atmos., 116, D02111 (https://doi.org/10.1029/2010JD014477)

Perşoiu A and 5 others (2017) Holocene winter climate variability in Central and Eastern Europe. Sci. Rep., 7, 1196 (doi: 10.1038/ s41598-017-01397-w)

Purcarea C (2018) Microbial life in ice caves in Ice caves. In Perșoiu A and Lauritzen S-E eds. Amsterdam, Netherlands: Elsevier, 173-187 (https://doi.org/10.1016/B978-0-12-811739-2.00008-5)
Quaedvlieg W and 7 others (2013) Sizing up septoria studies in mycology. 75, 307-390 (doi: 10.3114/sim0017)

Racovita EG (1927) Observations sur la glaciere naturelle dite 'Ghețarul de la Scărişoara'. Buletinul Societatii de Stiinte din Cluj, 3, 75-108

Racoviță G (1994) Bilan climatique de la grotte glacière de Scărişoara, dressé sur dix années d'observations. Travaux de I'Institute de Spéologie "Emil Racovitza", 33, 107-158

Racoviță G and Onac BP (2000) Scărişoara Glacier Cave. Monographic study. Ed. Carpatica, Cluj-Napoca, Romania. 140 p ISBN 973-98752-1-1

R development Core Team (2012) Development core. R: A language and environment for statistical computing.

Rime T, Hartmann M and Frey B (2016) Potential sources of microbial colonizers in initial soil ecosystem after retreat of an Alpine glacier. ISME J., 10, 1625-1641 (doi: 10.1038/ismej.2015.238)

Sayers EW and 32 others (2009) Database resources of the National Center for Biotechnology Information. Nucleic Acids Res., 37, D5-15

Schloss PD and 9 others (2009) Introducing mothur: open-source, platform-independent, community-supported software for describing and comparing microbial communities. Appl. Environ. Microbiol., 75, 7537-7541

Schoch CL and 59 others (2009) The Ascomycota tree of life: a phylum-wide phylogeny clarifies the origin and evolution of fundamental reproductive and ecological traits. Syst. Biol., 58(2), 224-239 (https://doi.org/10.1093/sysbio/syp020)

Skidmore ML, Foght JM and Sharp MJ (2000) Microbial life beneath a high Arctic glacier. Appl. Environ. Microbiol., 66(8), 3214 (doi: 10.1128/AEM.66.8.3214-3220.2000)

Sonjak S, Frisvad JC and Gunde-Cimerman N (2006) Penicillium mycobiota in Arctic subglacial Ice. Microb. Ecol., 52, 207-216 (doi: 10.1007/s00248-006-9086-0)

Spatafora JW and 14 others (2016) A phylum-level phylogenetic classification of zygomycete fungi based on genome-scale data. Mycologia, 108(5), 1028-1046 (doi: 10.3852/16-042)

Vishniac HS (2006) Biodiversity and ecophysiology of yeasts. In Rosa C and Gabor P eds. Heidelberg, Berlin: Springer-Verlag, 419-440

Wang Q, Garrity GM, Tiedje JM and Cole JR (2007) Naive Bayesian classifier for rapid assignment of rRNA sequences into the new bacterial taxonomy. Appl. Environ. Microbiol., 73, $5261-5267$

Whittaker RH (1960) Vegetation of the Siskiyou Mountains, Oregon and California. Ecol. Monogr., 30(3), 279-338 (doi: 10.2307/ 1943563)

Wickham H (2016) Ggplot2: elegant graphics for data analysis. New York: Springer-Verlag

Woudenberg JHC and 6 others (2015) Alternaria section Alternaria: species, formae speciales orpathotypes? Stud. Mycol., 82, 1-21 (https://doi.org/10.1016/j.simyco.2015.07.001)

Xia F and 8 others (2016) High-throughput sequencing-based analysis of endogenetic fungal communities inhabiting the Chinese Cordyceps reveals unexpectedly high fungal diversity. Sci. Rep., 6, 33437 (doi: 10.1038/srep33437)

Žák K, Onac BP and Perşoiu A (2008) Cryogenic carbonates in cave environments: a review. Quat. Int., 187, 84-96 (https://doi.org/ 10.1016/j.quaint.2007.02.022)

Zhang X, Yao T, An L, Tian L and Xu S (2006) Vertical profiles of bacterial DNA structure in the Pupuogangri IC (Tibetan Plateau) using PFGE. Ann. Glaciol., 43, 160-166 